\title{
THE PROCESS OF ARTIFICIAL INTELLIGENCE AND AUTOMATION HAS INCREASED THE NEED OF EMOTIONAL INTELLIGENCE AT WORKPLACE
}

\author{
DR. AJAY TIWARI. O.P ${ }^{1}$ \& DR. SARIKA SRIVASTAVA ${ }^{2}$ \\ ${ }^{1}$ Jindal Global University, India \\ ${ }^{2}$ PDP Trainer, India
}

\begin{abstract}
Artificial Intelligence + Emotional Intelligence = Mantra of Success and Survival in the World of Automation

The process of Artificial Intelligence and Automation is transforming the face of every industry and by 2030 it's going to have a greater impact on the way we live, think and work. The unchallenged growth of artificial intelligence is a double edged sword where it is making our lives sorted simultaneously shrinking the employment sector. Which is rising the fear of job erosion. In near future machines will ultimately render human capabilities more effectively and accurately because AI enables system has the potential to grasp knowledge, adapt to it and response accordingly without fatigue. If this happens to be true, it will only eliminate many jobs but also change the job demand with Increase task complexity, which is going to put extra pressure on physical and mental condition of our workforce.

“According to WHO reports around 450 million people are globally affected by mental illness." Irony is that people hesitate talking about their mental condition due to social stigma. Only two-thirds of people with a known mental condition such as anxiety, depression and co-occurring disorders seek medical help, rest unreported. Consequently resulting in suicides or other heinous crimes.

Today only work related stress has become one of the biggest challenge and in future it's going to increase many folds when we have to prove our worth to smart machines. Emotional intelligence becomes far more critical for anyone who wants to stay relevant in their field, to know how to deal with work pressure, increase productivity and to deal with mental pressure. To deal with such situation preventative measures becomes need of hour before the problem escalates and becomes more severe. This study is an attempt to bring out the positive and negative impact of Artificial intelligence and Automation on the world of work and working conditions and try to prove the importance and need of emotional Intelligence for our workforce in the age of Automation. Concluding with focusing on with the best possible solutions to deal with the future Technological changes

KEYWORDS: AI - Artificial Intelligence EI - Emotional Intelligence, EQ -Emotional Quotient ,Robots Resources'- Any Automatically Operated Machine that Replaces Human Efforts Replace, WEF- World Economic Forum
\end{abstract}

Received: Jun 08, 2020; Accepted: Jun 28, 2020; Published: Aug 11, 2020; Paper Id.: IJMPERDJUN2020734

\section{INTRODUCTION}

Mark Cuban, "Predicted that the world's first trillionaires will be those who work with AI. The two superpowers of today and tomorrow, $\mathrm{AI}$ and EQ, must work in a symbiotic relationship. Humans have devoted substantial time and effort towards developing AI tools. It's time that we wake up to the pressure AI is putting on humans to be far more emotionally intelligent. The success of our personal and professional endeavours depends on it." 
What if in future you have to report a virtual boss?? Because from recruiting to performance review the departments of 'robots resources' will rival 'human resources' by 2030. So in near future if you are attended by a robot at reception counter or robots filling fuel into your cars to diagnosing complex medical problems, or even performing complex surgeries don't wonder. If this happens to be true; Automation and AI might not only eliminate many jobs but will change the job demand with Increase task complexity which is going to put extra pressure on our workforce.

"Artificial intelligence" the most transformational technology is both exciting and frightening. Since Artificially intelligent (smart machines) can perform multiple tasks without fatigue it will bring in more efficiency to the tasks and minimize its time with this idea now many companies are replacing employees with virtual assistants; which is a great cause of worry for employment sector .Because half of the activities undertaken by the employees today would be automated in future.

According to Gartner's report, "These smart machines will soon become co-worker changing the modus operandi of how employees work. People will focus on people -related activities that require intuition, empathy and interpersonal skills".

The process of Automation in industry is making our work easier but becoming a big challenge for us by making our jobs tough and increasing work related stress. "According to WHO reports around 450 million people are globally affected by mental illness". Irony is only two-thirds of people with a known mental condition, such as anxiety, depression and co-occurring disorders seek medical help rest unreported .Consequently resulting in suicides or other heinous crimes. Before the problem escalates and becomes more severe to deal with such situation preventative measures becomes need of hour. Here emotional intelligence becomes more essential for anyone and everyone who not only wants to stay relevant in their field to avoid work related stress and increase productivity.

Emotions are the most important part humans and without emotional intelligence artificial intelligence is incomplete; so if you are concerned that your job might be one day outsourced to technology the best thing you can do is to work on Emotional intelligence (Life skills) these skills might not only save your job but will also make you relevant in competition with smart machines.

\section{RISING CONCERNS}

A study Mckinsey Global Institute suggests that by 2030 intelligent agents and robots could replace as much as 30 percent of the world's current human labour that depending upon various adoption scenarios, automation will displace between 400 to 800 million jobs by 2030 requiring as many as 375 million people to switch job categories entirely.

Be concerned if you are in one of these fields like agriculture, transport industry banking sector, Library, Knowledge Resource centre, Nurse, Legal Assistant, Telemarketer, Data Entry Professional, Security Guards, Financial Adviser, Receptionist you might be surprised that robots are capable in replacing humans in all such jobs and many other jobs too, Sounds strange but its true in next 10 years you may lose your job to robots. We can already observe reductions in employment in some sectors, and those who are employed work under tremendous time pressure and continued organisational changes. How could such a shift not cause fear and concern especially for the world's vulnerable population.

It's the right time we should wake up to the pressure that Artificial Intelligence is putting on Humans to avoid future setbacks like job erosion as these smart machines have human like capabilities that might Think like humans, Act 
like humans or can do much more than humans without fatigue. These smart machines are becoming strong competitors for all of us. If technology takes over a larger number of tasks India will face the huge impacts of AI and automation relative to other countries. Because of its large population still not ready to face the changes and challenges which will affect us in aspects from jobs to quality of life.

\section{VISIBLE IMPACT OF ARTIFICIAL INTELLIGENCE AND AUTOMATION ON INDUSTRY}

Artificial Intelligence and Automation has transformed the face of industry and in next few years from now it's going to have a greater impact on the way we live, think and work. Today we are not dealing with deaf and dumb machines anymore with the advancement of technology we have built the machines that can not only interact with us but can react accordingly in fact most of us are interacting with artificially intelligent devices in some form or another on a daily basis.

Artificial Intelligence and Automation is changing every industry particularly the tasks which once was considered dangerous for humans or beyond the human capabilities are happening in just a pinch. And this isn't just confined to Earth in fact technology is bringing us closer and closer to the unknown world of stars with AI leading the way is making it possible what was once a dream and considered impossible like driverless cars and fighter planes all credit goes to AI. Statics reveals that tasks such as diagnosing disease to performing critical surgeries AI is performing even better than humans in healthcare sector, same is the case In Education sector classrooms and Textbooks are digitized and can be accessed from anywhere, today virtual tutors assist human instructors and facial analysis gauges the emotions of students to help them determine who's struggling with the concepts.

In Manufacturing and Production AI powered robots work alongside humans to perform a limited range of tasks like keeping equipment running smoothly. This is just a glimpse. Artificial intelligence is disrupting major business process in every industry the list of AI's application in industry is endless that's why every industry is heavily investing in automation.

\section{DIRECT IMPACT ON WORK AND WORKING CONDITIONS RESULTING INCREASED STRESS AND HEALTH ISSUES}

The application of AI to an extraordinarily wide range of tasks will have a direct impact on the world of work and working conditions. Both positive and negative effects could be seen in multiple directions. The extensive use of AI at workplaces will not just influence employment, wages and job satisfaction but also increase stress and health issues.

A report by Infosys and Gartner predicts that automation and AI might lead to elimination of middle management roles over the next decade "We will need fewer people as management tasks such as collection data supervising actions and ensuring compliances will be completed by algorithm and robosses".

In this case the automation and AI might not only eliminate many jobs but will also change the job requirements with Increase task complexity which is going to put extra pressure on our workforce. Today only work related stress has become one of the biggest challenge and in future it's going to increase many folds when we have to prove our worth to smart machines.

\section{INCREASING NEED OF EMOTIONALLY INTELLIGENT WORKFORCE}

$\mathrm{AI}$ and Automation is eliminating the need of man power and continue to do so in future also by replacing humans in many fields; but cannot replace humans completely because to do any of the doing we will still need humans to determine what 
to do, as there are still many jobs that only humans can do. Emotions like touch, care ,love, affection ,intuition motivation, persuasion, social understanding, empathy, sympathy are the natural qualities and cannot be replicated or replaced by any sort of machine.

The Doctors, Nurses, Assistant, Telemarketer, Security Guards, Financial Adviser, Receptionist can be replaced by AI robots in future but if you are trained with hospitality and caretaking skills you will be preferred over a robots. It means jobs are going to be knowledge-centric and talent centric. The professions in which the process of Automation and AI will have the least impact will be those jobs that require high cognitive skills and direct contact with other people. The skills like persuasion, social understanding and empathy are going to become differentiator capabilities like EI/EQ will become more and more prized over the next decade.

'HBR Review' explains "Those that want to stay relevant in their professions will need to focus on skills and capabilities that artificial intelligence has trouble in replicating — understanding, motivating, and interacting with human beings."

We need to be flexible in our skills and approach. Cognitive skills, Social skills, Emotional skills and Technological skills are the most important skills needed for the 21 st century but unfortunately graded secondary and missing from standard curricula. In a world where change is constant analysis indicates that our adaptive intelligence will be crucial for survive.

Senescing about future Emotional Intelligence must be incorporated into educational programs and professional development. Here the employee and employers responsibility also becomes important to devote resources and time towards EI learning. So if you want excel in your career, avoid negativity from your life the best thing can be done is to work on emotional intelligence .These skills might not only save your job but will also help in dealing with emotional outbursts.

\section{EMOTIONAL INTELLIGENCE IN TECHNICAL TERMS}

PeterSalovey with his colleague John Mayer put forth one of the first formal theories of emotional intelligence in 1990. They coined the term and described it as "the ability to recognize, understand, utilize, and regulate emotions effectively in everyday life" Later researcher and psychologist Daniel Goleman in his book Emotional Intelligence in 1995 introduce it into the mainstream.

In practical terms being aware that emotions can drive our behaviour and impact people (positively and negatively) especially when we are under pressure. Emotional intelligence is also known as Emotional quotient, People Skills, or Life Skills.

\section{EMOTIONAL INTELLIGENCE AND TECHNICAL SKILLS:-THEIR IMPORTANCE AT WORKPLACE}

Emotional intelligence is not genetic a sort of trait, "you have it or you don't", but these are the skill set that can be learned and improved upon through rigorous practice. In fast changing business world these skill set will become a vital factor in personal and professional success.

Self-Awareness:- Self -Awareness is the most important part of emotionally intelligent person through self awareness one can look deep into (self) and can explore inner self strength, weakness, fear and life gaols by exploring 
inner self it become very easy to work on weakness overcome the fears and make a proper road map to achieve the goals. People who know their strengths and weaknesses perform better and better this also boosts their confidence and productivity.

\section{Positive Effect of Self-Awareness}

- Better able to deal with stress

- Manages time in better way

- Better able to take feedback and criticism in constructive way.

Self-Monitoring:- involves taking a pause between a feeling and an action. People who monitor their feelings and actions typically don't allow themselves to become too angry or take impulsive decisions. They are cool minded people and think before they react.

\section{Self -Monitoring at professional front helps in -}

- Establishing Work Parameters

- Monitor Work Progress.

Self-Motivation:- Self-motivation is our internal drive to achieve, produce, develop and not to stop but keep moving forward. It is the force that keeps pushing you to go on When you are thinking to quit or you just don't know how to start, Self motivated people are highly productive and have positive mind-set they are very effective in whatever they do.

\section{Self Motivated People are}

- Naturally curious person

- Refuse to give up easily

- $\quad$ Pro-active people

Empathy: The ability to put yourself "in someone else's shoes" is to understand the other's situation. Empathy is a critical skill for the leaders. It contributes to an accurate understanding of employees their perceptions and concerns. It also establishes a good flow of communication between the staff and higher authority this is the only way to create a healthy work atmosphere in any organisation because you can sense what others want and they are getting it from you or not.

\section{Empathy at Workplace}

- Help an employee with personal problems.

Social Skills: Social skills are also called "interpersonal skills" these skills play very important role Almost every job requires social skills. If you work in a team, you need to be able to get along with others. If you work with clients, you must listen attentively to their questions and concerns. If you are a manager, you will be called upon to motivate employees. 


\section{Importance of Social Skills at Workplace}

- Employees with strong social skills are typically team players.

- They rather than focusing on their own success first help others develop and shine.

- They can manage and easily solve disputes, also are excellent communicators, and master at building and maintaining relationships.

Technical Skills: Technology is gradually infiltrating every part of our work and it's likely to continue to do in the future also. A technical skill is not just going to become confined for the people in technical jobs. But will increasingly become important for everyone regardless to any industry or job role.

\section{Technical Skills make you}

- Ready for changes in the future

- $\quad$ Far more valuable in competitive job market.

- Confident and comfortable in your role.

- First in line for a job promotion.

- $\quad$ Encouraging you to work harder and provide even better results.

\section{EMBRACE THE REALITY AND DOUBLE DOWN THE EFFORTS FOR FUTURE}

The two superpowers of today and tomorrow AI and EI are two sides of the same coin on one side is technological competence and on the other side are emotions that comes almost automatically to humans; we react on instinct. We can easily interpret the emotions and feelings of those around us. This automatic understanding cannot be taught to a machine. People who have both will easily be able to gel up and those not would have hard time.

Below are the suggestions to deal with the technology driven challenges.

- Welcome the changes in industry and accept the challenges. As technology is gradually infiltrating every part of our work and it's likely to continue to do so in the future, so don't try to swim against the flow of water.

- Don't fight the progress of technology; nor run away from it. But be technology friendly. Try to learn new skills.

- Invest time in developing your emotional intelligence. Recognize your strengths, weaknesses and fears.

- Start focusing on how you can be better than others; take one step further by seeking out training or professional help.

- Manage your negative emotions. When feel depressed seek proper medical help look at the positive side of picture. Try your level best to bounce back from adversities.

- Try to focus on skills like persuasion, social understanding, empathy, motivation as these are going to become a differentiators in future because artificial intelligence will always have trouble in replicating these skills .

- $\quad$ Practice Self -Awareness, Empathy in your routine life. Keep yourself physically fit. 
- Thinkwin-win situation that will lead to mutual benefit because EI and AI have the ability to improve outcomes.

\section{CONCLUSIONS}

The process of Artificial intelligence and Automation for better or worse will have a direct impact on the world of work and working conditions. People predict massive job loss due to AI and Automation in industry no doubt the existing jobs will be disrupted by new technology but this will also pave the way for new jobs. The jobs will be knowledge-centric and talent centric.

The WEF indicated that the new positions will require additional skills for managing the interface between technology and humans. Artificial Intelligence is going to bringing new opportunities and greater efficiencies to both work and workforce. Which is going to increasing employee and organisation focus on unique human cognitive capabilities that machines simply cannot replicate. To check and manage machines to function properly humans will still be needed

\section{WORKS CITED}

1. Business Insider India: Latest News on Tech, Careers \& Jobs, Finance, Money, Politics, Life \& Strategy. Retrieved from https://www.businessinsider.in

2. City University of Hong Kong. Retrieved from https://www.cityu.edu.hk

3. Rai, Dona. "Assessment of Emotional Intelligence and Emotional Maturity of Undergraduate Students." International Journal of Humanities and Social Sciences (IJHSS) 6.4 (2017): 75-80.

4. Communications, F. I. U.- D. Retrieved from https://www.fiu.edu

5. The Balance Careers. The Balance Careers. Retrieved from https://www.thebalancecareers.com

6. PositivePsychology.com - Helping You Help Others. Retrieved from https://positivepsychology.com

7. Khatoon, Nuzhath. "Emotional stability, self professional development and its role in effective teaching." International Journal of Business and General Management, 4, 914 (2015).

8. Tech News, Trends \& Professional Development Resources | Built In. Retrieved from https://builtin.com

9. HBR Ascend. Retrieved from https://hbrascend.org/home

10. Home. Retrieved from https://www.rp.edu.sg

11. Fiji National University. Retrieved from https://www.fnu.ac.fj/new

12. University Of Worcester. Retrieved from https://www.worcester.ac.uk

13. Leeds Beckett University. Retrieved from https://www.leedsbeckett.ac.uk

14. Ali, Salimabarkat, and Anjum Ara. "Intelligence as a determinant of academic achievement: A comparative study of high achievers and underachievers. "International Journal of Humanities and Social Sciences (IJHSS) 6.6 (2017): 79-88.

15. The Da Vinci Institute: School of Business Leadership. Retrieved from https://www.davinci.ac.za

16. Great Learning: Top-Ranked Professional Courses for Career Success. Retrieved from https://www.mygreatlearning.com

17. Forbes. (2020, Jul. 02). Retrieved from https://www.forbes.com/\#22543fe92254 
18. Danquah, Emelia., and Theophilus B. Wireko. "The impact of each element of emotional intelligence on customer service delivery: A customer satisfaction perspective." International Journal of Sales \& Marketing Management Research and Development 4.2 (2014): 9-20.

19. The best content, news, and resources for IoT. Retrieved from https://www.iotforall.com

20. Palatine HS / Homepage. Retrieved from https://adc.d211.org/Domain/8

21. Independent Training Provider | Steadfast Training Ltd - Steadfast Vocational Training. Retrieved from https://www.steadfasttraining.co.uk

22. Just Imagine. Retrieved from https://justimagine.aurecongroup.com

23. www.usc.edu.au. Retrieved from https://www.usc.edu.au 